\title{
The role of goal concordance on happiness and college students' academic performance
}

Lumontod, Robinson Z., III $\square$

Central Luzon State University, Philippines (robinsonlumontodiii@gmail.com)

Received: 8 January 2019

Available Online: 17 May 2019
Revised: 27 February 2019 DOI: $10.5861 /$ ijrsp.2019.4000

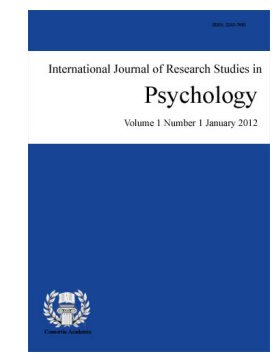

Accepted: 11 April 2019 Online ISSN: 2243-769X

OPEN ACCESS

\section{Abstract}

For decades, studies on goal concordance had documented its significant role in individuals' performance and success in many aspects of life. Previous researchers claimed that goal concordance buffers happiness (Sheldon \& Elliot, 1999) and task performance (Deci \& Ryan, 2000). But studies on the possible influence of goal concordance and happiness in academic context remained unclear, especially in the Philippine academic setting. To shed light on the remaining question in the literature, this study focused on determining the possible association between goal concordance and happiness with college students' academic performance. The study was conducted at the Central Luzon State University in the Philippines. 300 college students participated in the current investigation. Using the correlational and test of difference analyses, this study had come up with several important findings. A significant relationship between goal concordance and academic performance was found. In addition, the significant association between happiness and academic performance was also noted. However, goal concordance and happiness had no significant relationship. Moreover, the finding shows a significant difference between the two groups of students: college students with self-concordant goals had higher academic performance than those with nonconcordant goals. Lastly, there is no significant difference in happiness between students with self-concordant and nonconcordant goals. Both practical and theoretical implications are discussed.

Keywords: goal concordance; happiness; academic performance; Filipino college students; academic success 


\section{The role of goal concordance on happiness and college students' academic performance}

\section{Introduction}

Previous studies on goal concordance yielded consistent results that shed light on the importance of pursuing personal goals on achieving success. In the academic setting, pursuing a self-concordant academic goal would result in academic progress and success (Vasalampi, Salmela-Aro, \& Nurmi, 2009; Koestner, Lekes, Powers, \& Chicoine, 2002). Previous findings simply connote that goal concordance significantly predicts better adjustment and academic performance in college students (Sheldon \& Houser-Marko, 2001). As a result, pursuing personal goals lead to a high degree of goal achievement, contentment, and happiness (Sheldon \& Elliot, 1999). In short, self-concordant goals provide internal fuel which may result in greater motivation and well-being. Because internal motivation has a significant role in academic achievement (Ghamari, 2011), it may be plausible to argue that students who have self-concordant goals tend to be more successful in the academic endeavor.

Apparently, plans and goals are determinants of human behavior (Alispahić, 2013). In the academic setting, however, students' plans do not always prevail. In fact, Blackmon (2013) revealed that $64 \%$ of college students were enrolled in courses that do not fit with their personal interest. The tantamount number of students caught in the same situation may be found in schools around the world. Unfortunately, due to some underlying circumstances (e.g. financial, mental ability), many students end up pursuing academic courses that do not reflect their personal interests. This paper suspects that, although no data available, the same circumstance happens in the Philippine academic settings. A considerable number of students might have constrained by uncontrollable external factors that held them back from adhering with their personally defined college degree. What would happen to students who failed to follow their dream college courses? This question is the fundamental reason why the current study had set forth to partly respond to the question at hand. Understanding the factors that could increase and/or detriment students' academic performance may be helpful for future educational interventions.

Although studies on motivation and goal setting provide rich data on the role of autonomous goal on success in many aspects of life, one question remains untapped. Does the principle of self-concordance operate across the world especially in the individualistic culture like the Philippines? The previous study by Sheldon et al. (2004) explored self-concordance and subjective well-being in several Asian cultures. However, the Philippines was not included in the latter investigation leaving the influential power of self-concordance goal on Filipino college students' happiness and academic performance unclear. Do students with self-concordant goal academically perform better and happier than their counterparts with a nonconcordant goal? At this point, this paper can only assume that goal concordance is a significant factor that influences college students' happiness and academic performance. In addition, this study may be the first to investigate the possible connection between self-concordant goal, happiness and academic performance in Filipino college students.

\section{Review of Related Literature}

\subsection{Goal Concordance and Success}

Similar to Sheldon et al. (2004), this study defined goal concordance as a tendency for a person to pursue a personally defined goal. People with self-concordant goals pursue something that directly reflects their interests and aspirations. In contrast, people with nonconcordant goals pursue something that is not congruent with personal aspirations. From this simple definition, college students who pursued their dream college courses at the university can be considered to have self-concordant goals. In contrast, students who were forced or externally motivated (e.g. influenced by parents or financial issues) to pursue a college course they did not intend 
The role of goal concordance on happiness and college students' academic performance

to enroll in can be considered to have a nonconcordant goal. Because a personally defined goal is instrumental in academic success (Vasalampi, Salmela-Aro, \& Nurmi, 2009), students with nonconcordant goals may find difficulties in their entire academic journey.

For decades, studies on goal concordance yielded significant contribution on how individuals achieve success even in challenging tasks. Previous findings led to the understanding that self-concordant goals are more achievable than the externally motivated ones. As a result, people who autonomously pursue a personally defined goal tend to be more successful than their counterparts. Interestingly, self-concordant goals do not only lead to ultimate success but also make the tasks associated with the goal easier to achieve (Werner, Milyavskaya, Foxen-Craft, \& Koestner, 2016). Therefore, a goal can be more accessible if it is aligned with an individual's passion and interest. This leads to the assumption that internal motivation is a better predictor of an individual's performance and behavioral outcome (Koestner, Powers, Pelletier, \& Gagnon, 2008). Adhering to internal motivations may not only result in better performance but also in a higher state of happiness (Deci \& Ryan, 2000). Ultimately, as Sheldon and Hower-Marko (2001) suggested, the self-concordant goal has an incremental effect on performance and goal attainment. The latter researchers believed that a successful self-concordant goal boosts performance and goal attainment of the succeeding tasks which in turn enhances the sense of achievement.

The ability to follow one's interest determines the likelihood of achieving the goal. An individual who is primarily driven by internal motivation tends to perform well in the tasks associated with the goal (Gillet, Vallerand, Lafrenie're \& Bureau, 2013). Moreover, the freedom to choose a course of action promotes better performance and task engagement (Ntoumanis et al., 2014). Ultimately, to attain any goal, it must be aligned with an individual's interest and orientation (Lee, Mclnerney, Liem, \& Ortiga, 2010). In contrast, externally driven goals may impair the overall process of attaining success.

Goals that are not aligned with personal interests may affect not only the individuals' performance but also the psychological health (Boudreaux \& Ozer, 2013). While the internally motivated individuals tend to successfully achieve better mental health (Michalak, Klappheck, \& Kosfelder, 2004). The absence of internal motivation could hinder a person from bringing out his/her full potential. However, pursuing a self-concordant goal requires social support to make those goals thrive through the end (Koestner, Powers, Carbonneau, Milyavskaya, \& Chua, 2012; Koestner, Powers, Milyavskaya, Carbonneau, \& Hope, 2015). In the case of college students, having family support and freedom to choose their academic path could potentially shape their fate in college. If all previous findings can be held true in academic settings, then students with self-concordant goals would most likely succeed in their academic journey.

\subsection{Goal Concordance and Happiness}

Previous findings had been consistently showing the significant association between goal concordance and affective outcome. In most cases, pursuing personal goals increases happiness. Happiness in this study is defined as an individual's perception of his/her overall sense of life enjoyment (Veenhoven, 2010). Happy people believed to have joyful life experiences. One of the factors that shape one's emotional state is self-concordance goal adherence. The implementation of autonomous goals promotes motivation which in turn result in a desirable account of emotional experience (Uusiautti, 2014). Doing things that are in line with one's strengths and talents allow a person to define the meaning of life. This may sound subjective; that is the meaning of one's life is an innate experience and therefore not accessible from the external world. Nonetheless, realizing the meaning and purpose of life could have a tremendous impact on one's behavioral engagement and well-being. Individuals who are driven by personally defined goals tend to have a high level of subjective well-being (Headey, 2006). Chen, Lee, Pethtel, Gutowitz, and Kirk (2012) found the same result. The latter finding pointed similar trajectory; people who are following self-concordant goals are intrinsically motivated and such undertakings made them happier. 
In the workplace settings, the influence of goal concordance on employees' happiness was also noted. Judge, Bono, Erez, and Locke (2005) concluded that a self-concordant goal was associated with employees' job satisfaction. Achieving autonomous goals yield positive emotions which also increases performance (Pekrun, Elliot \& Maier, 2009). In short, performance and success may be the function of self-concordant goal pursuit and happiness while performing the tasks associated with the self-concordant goal. One can assume that positive emotions shape task performance. However, the outcome of the task performance may also influence one's emotional state. This assumption may suggest that task performance and happiness have reciprocal causal interaction.

In the academic setting, pursuing a personally defined goal is essential to students' happiness. Tabbodi, Rahgozar, and Abadi (2015) found the association between happiness and students' academic achievement. Happier students tend to achieve higher academic performance than their counterparts. It seemed clear that students' emotional state may have played an important role in the attainment of any academic goal (Daniels et al., 2009). Pursuing a self-concordant goal is one of the factors that could boost students' interest in academic task and well-being (Randler, 2009). The failure to adhere to the autonomous goals may then affect students' perceived value of academic endeavor which may result in poor academic performance. This may be the underlying reason why Neuville, Frenay, and Bourgeois (2007) suggest that educators should promote students' perceived importance of the academic undertaking. This recommendation stems from the observation that students with high perceived importance of the academic undertakings tend to maximize learning strategies than students who had low perceived value of the task. As a result, students who have high task value tend to successfully finish the tasks associated with the goal being pursued (Soule, 2009). Thus, students who positively perceive the academic tasks were able to build resilience throughout the course of the goal (Sung \& Tsai, 2014). Helping students discover their strength and interest enable them to make necessary adjustments and boost their well-being (Harachiewicz \& Hulleman, 2010). In essence, school systems have a vital role in fostering students' success in college. In fact, Panahi, Pahani, and Sobhani (2015) found that, through proper guidance, students could develop a positive cognitive pattern that could significantly increase students' performance and happiness.

\subsection{Happiness and Academic Performance}

For decades, the link between happiness and academic performance had been investigated. However, results from previous queries were not ubiquitous. The varied findings may have stemmed from the complexity of happiness that is characterized by multiple influential factors (Datu \& Valdez, 2012). In some studies, happiness was found to be associated with academic performance (Manzoor, Siddique, Riaz, \& Riaz, 2014; Mohammadi, 2015) and academic motivation (Hassanzadeh \& Mahdinejad, 2013). Most of the previous studies revealed that happiness increased academic performance, and high academic performance also increases happiness.

In contrast, some findings suggest the opposite trajectory. For instance, Bücker, Nuraydin, Simonsmeier and Schneider (2018) found that students' well-being was somewhat unrelated to students' academic performance. The finding argued that well-being and academic performance were two independent constructs. A similar finding was noted between life satisfaction and academic performance (Malik, Nordin, Zakaria, \& Sirun, 2013). Academic success does not necessarily predict happiness (Chacko \& Abraham, 2017). Instead, self-efficacy was found to be associated with adolescents' well-being (Datu, 2013; Rahimi Pordanjani, Yahyanezhed, \& Moharer, 2014).

Academic performance is also a complex and multifaceted construct similar to happiness. It is shaped by several influential factors. Students' family dynamics alone could largely shape academic performance (Mushtaq $\&$ Khan, 2012). Students with stressful family background had a poor academic outcome. Social status may also influence academic performance. Students with high financial status were found to have lower academic performance than poor students (Tuntiwarodom \& Potipiti, 2008).

Aside from socio-demographic characteristics, motivational factors could also influence how students deal 
The role of goal concordance on happiness and college students' academic performance

with academic demands and challenges. Previous studies had documented the significant influence of motivation on students' performance. Intrinsic motivation would most likely predict students' academic performance (Khoshnam, Ghamari, \& Gendavani, 2013; Hosseini, Pishghadam, \& Vahidnia, 2014) not the length of time spent in the academic task (Nonis \& Hudson, 2006). Students who are internally motivated tend to effectively carry out academic tasks. Overall, previous studies consistently suggest the importance of goal concordance and happiness on task performance. But the findings did not suggest the same causal and correlational trajectory. All the assumptions lead to a relevant question as to whether or not latter pieces of evidence can serve as bases of macro-level generalization.

\subsection{Theoretical Framework}

The motivational factors that shape students' academic behavior could partially, if not largely explained by Self-Determination Theory (Ryan \& Deci, 2000). The SDT posits that people are mainly influenced by psychological needs. These needs pertain to competence, connectedness, and autonomy. Competence refers to a person's tendency to deal with challenging tasks by themselves. A competent person is more likely to trust his/her innate abilities to succeed. The second need is the need to connect with others. This need influences people to build social strand that allows them to link with the social context. Lastly, the need for autonomy. People tend to exercise the freedom to execute preferred actions rather than being subservient to others.

The basic psychological needs as argued by the Self-Determination Theory remarkably, as found in the large array of literature, explain people's behavior in different settings. For instance, Niemiec and Ryan (2009) found that both intrinsic and autonomously defined motivation resulted in better engagement and learning outcome among students. The study further suggests that contextual support for autonomy, competence, and relatedness elicit the increase not only in academic engagement and performance but also happiness. In fact, students with autonomous academic goal were less likely to procrastinate (Senécal, Koestner, \& Vallerand, 1995). In the absence of the basic psychological needs, Deci and Ryan (2000) suggested that people's level of motivation, performance, and well-being dwindle.

The predictive ability of SDT on people's behavior can also be seen in workplaces. Previous findings found a similar result in corporate and health-related context (Deci et al., 2001; Ng et al., 2012). The finding suggests that the three basic psychological needs (competence, autonomy, and relatedness) were consistent in influencing individuals' motivation. It is important to note that basic psychological needs are intrinsically driven. The Self-Determination Theory argues that, in general, people tend to pursue intrinsically motivated goals rather than extrinsically motivated ones. The success of the intrinsically driven pursuit is directly intertwined with a high sense of competence, relatedness, and autonomy (Vansteenkiste, Lens, \& Deci, 2006). However, the attainment of psychological needs seems to be dependent on contextual support. Thus, the context from which a person is operating determines the progression of psychological needs. The adolescents, for instance, need parental support to develop autonomy that will, later on, translate into happiness (Niemiec et al., 2006). Parental autonomy support facilitates the development of intrinsic motivation and, possibly, resilience among young people (Joussemet, Landry, \& Koestner, 2008). Understanding the motivational forces behind students' academic performance may require the reconsideration of the multilayered factors (Hidi \& Harackiewicz, 2000).

In this study, the SDT can shed light and further understanding as to how students with self-concordant and nonconcordant academic goals behave in academic settings. Taking the basic psychological needs into consideration, the present investigation assumes that students with a self-concordant academic goal (intrinsically defined goal) are more academically successful than those with a nonconcordant goal (externally defined goal).

\subsection{Current Study}

Previous findings had shown the significant influence of goal concordance on performance. Goals that are in line with the individuals' interest tend to be easier to achieve which often result in better performance. This 
achievement will later translate to higher happiness. In the academic setting, however, the link between goal concordance, happiness, and academic performance has not been investigated in the Philippines. This study assumed that students' happiness and academic performance is somehow the function of goal concordance. Following this assumption, students who are enrolled in courses they intended to enroll in college are happier and more academically successful than students who are enrolled in college courses they don't personally yearn. Thus, this investigation has focused on exploring whether or not goal concordance is significantly influencing the trajectory of students' happiness and academic performance. Lastly, this study also explores the influence of happiness and goal concordance on students' academic performance.

\section{Method}

\subsection{Design}

This study employed a correlational design which aimed at understanding the link between self-concordant goal and happiness with academic performance. Goal concordance was assessed using one simple question answerable by "Yes" or "No". "Are you enrolled in your preferred college course?" Students who answered "Yes" were considered to have pursued a self-concordant goal (coded as 2). While students who answered "No" were considered to have taken nonconcordant goal (coded as 1). The college students' happiness level was measured using the Subjective Happiness Scale (Lyubomirsky \& Lepper, 1999). This scale was chosen due to its ability to conduct quick happiness assessment. Unlike other happiness scales, the Subjective Happiness Scale is shorter making it more suitable for students. The SHS is a 7-point Likert scale with higher scores indicating a higher level of happiness. Lastly, students' GPA was used to assess the participants' academic performance. It is important to note that GPA varies in many universities. In this study, the participants' GPA ranges from 5.0 to 1.0 ( $5=$ Failure, $1=$ Excellent $)$ was based on the Central Luzon State University grading system.

\subsection{Participants}

The 300 college students of Central Luzon State University with age ranging from 16-24 years old $(\mathrm{M}=$ $17.68, \mathrm{SD}=1.27$ ) were purposively selected during the second semester of the academic year 2017-2018. 150 of the participants were enrolled in their personally chosen college courses while the other 150 were enrolled in courses they did not want. Overall, the participants were two groups: with a self-concordant goal (150 students who were enrolled in their preferred college courses), with a nonconcordant goal (150 students who were enrolled in undesired college courses). The data gathering commenced by initially asking students whether or not they personally selected the college course they enrolled in. Aside from the verbal response, participants also indicated their answer on the first part of the scale where the written question appeared. The process continued until the desired number of participants on each group was reached.

\subsection{Ethical Considerations}

All participants were informed about the purpose and nature of the study. The participants' participation was purely voluntary. The students were also informed about their rights to withdraw before, during, and after the actual data gathering without any consequences. The anonymity and the confidentiality of the information gathered were assured.

\subsection{Data Analysis}

There were two statistical analyses conducted in this study. First, the association between happiness and academic performance was analyzed using Pearson Moment Correlation. While the correlation between goal concordance and happiness with the academic performance was tested using the Point-Biserial Correlation. Secondly, the influence of happiness and goal concordance was analyzed using Multiple Linear Regression analysis. Lastly, the difference in students' happiness and academic performance between the two groups of 
The role of goal concordance on happiness and college students' academic performance

students (enrolled in desired courses and enrolled in undesired courses) was tested using Independent Samples t-Test.

\section{Results}

The main focus of this investigation was to examine whether goal concordance has a significant link with students' happiness and academic performance. This section of the paper indicates the results of the conducted statistical analyses.

\section{Table 1}

Academic Performance (GPA) and Happiness Level $(N=300)$

\begin{tabular}{lccc}
\hline & Mean & SD & Description \\
\hline GPA & 2.23 & 0.33 & Very Good \\
Happiness & 4.78 & 0.88 & Average \\
\hline
\end{tabular}

Students' academic performance was found to be very good $(M=2.23, S D=.33)$ based on the university grading system. While the overall score of students on the SHS was average $(M=4.78, S D=.88)$. This may suggest that, overall, the participants had a neither low nor high level of happiness.

\section{Table 2}

The Relationship for Goal Concordance and Happiness with Academic Performance (GPA) $(N=300)$

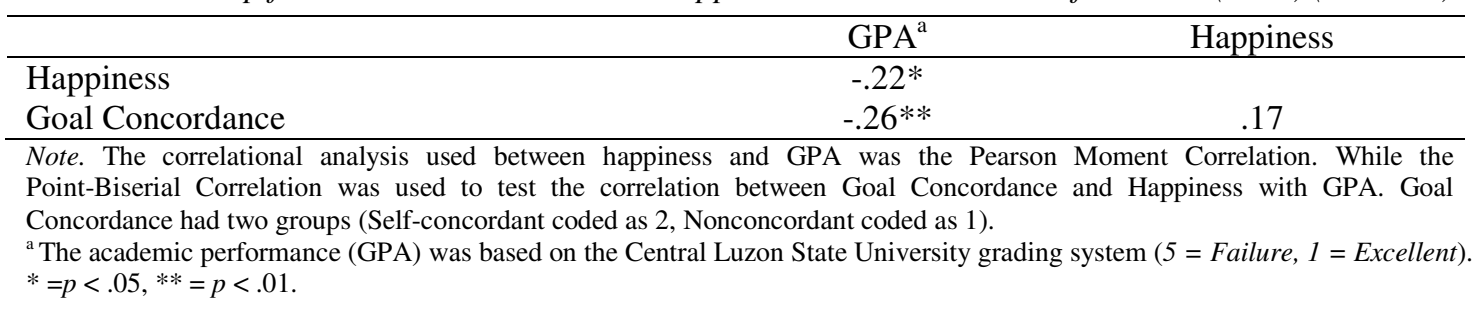

The correlation analysis results suggest that students' happiness had weak negative significant relationship with academic performance $(r=-.22, p=.017)$. Likewise, goal concordance was found to have significant weak negative relationship with academic performance $\left(r_{\mathrm{pb}}=-.26, p=.005\right)$. However, goal concordance failed to establish significant relationship with happiness $\left(r_{\mathrm{pb}}=.17, p=.07\right)$.

\section{Table 3}

Multiple Regressions on Happiness and Goal Concordance on Academic Performance

\begin{tabular}{lcccccc}
\hline \multicolumn{1}{c}{ Variables } & $\beta$ & $T$ & $p$ & $R$ & $R^{2}$ & $F$ \\
\hline Happiness & -.069 & -2.01 & .047 & .32 & .102 & 6.319 \\
Goal Concordance & -.154 & -2.55 & .012 & & & \\
\hline
\end{tabular}

The multiple regression analysis above shows that happiness and goal concordance both significantly predicted academic performance, $R^{2}=.102, F(2,297)=6.319, p=.003$. The result further indicates that $10.2 \%$ of the variance of students' academic performance is accounted for by happiness and goal concordance. While the $89.8 \%$ can be accounted for latent variables not included in the model. Lastly, happiness $(\beta=.069, p=.047)$ and goal concordance $(\beta=.154, p=.012)$ had significant individual influence on academic performance.

The Independent Samples t-Test results (see Table 4) suggest that the happiness level of students who had self-concordant goal $(M=4.93, S D=.78)$ and those with nonconcordant goal $(M=4.63, S D=.96)$ did not significantly differ $(t(298)=-1.835, p=.069)$. However, the academic performance of students with self-concordant goal $(M=2.15, S D=.27)$ was higher than those with nonconcordant goal $(M=2.32, S D=.36)$. The difference was highly significant $(t(280)=2.897, p=.005)$. 


\section{Table 4}

Happiness and Academic Performance (GPA) Means for Self-Concordant and Nonconcordant Goals $(N=300)$

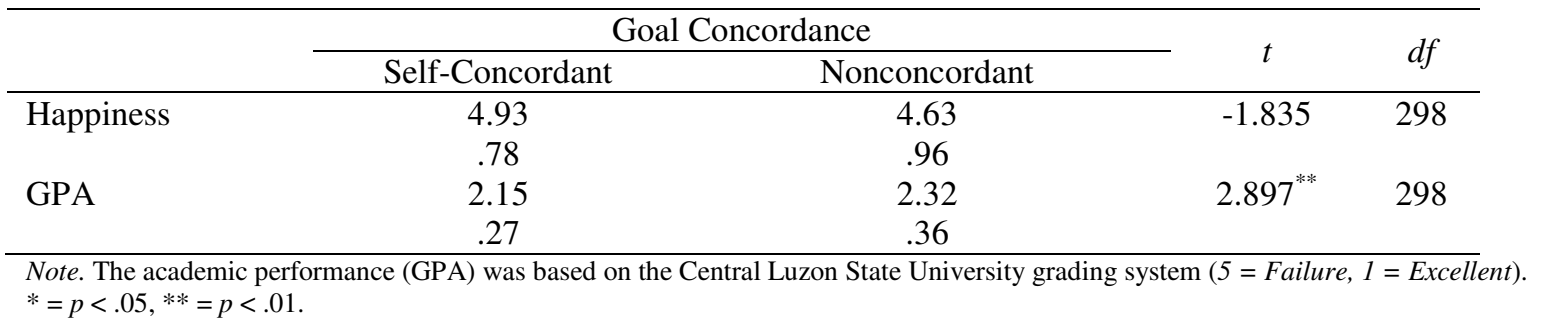

\section{Discussions}

The main goal of this study was to determine the relationship between goal concordance and happiness with academic performance among college students. The difference in happiness and academic performance level between students with self-concordant and nonconcordant goals were also assessed. Interpretations and theoretical implications are discussed in this section.

\subsection{Goal Concordance, Happiness, and Academic Performance}

Although weak, the relationship between happiness and academic performance was significant. The weak but significant relationship was also found between goal concordance and academic performance. However, goal concordance and happiness had no significant link with one another. However, goal concordance and happiness both significantly predicted students' academic performance. The test of difference echoed the non-significant link between happiness and goal concordance. The level of students' happiness did not significantly differ between those with a self-concordant and nonconcordant goal. In contrast, students with a self-concordant goal had higher academic performance than those with a nonconcordant goal. The findings of this study, therefore, support and dispute previous studies.

First, the significant relationship between happiness and academic performance corroborate previous findings of Mohammadi (2015), Manzoor, Siddique, Riaz, and Riaz (2014) and Tabbodi, Rahgozar, and Abadi (2015). The latter pieces of evidence suggest that happiness may boost academic performance resulting in higher academic performance. If this rationalization can be held true in all cases, then happy students should always benefit from having a positive effect. However, the observed relationship between happiness and academic performance cannot be held ubiquitous. There might be several factors that may have shaped happiness making it an elusive and complex construct. For instance, at least one study found that happiness and academic performance were not associated with one another (Malik, Nordin, Zakaria, \& Sirun, 2013). One possible explanation may be that happiness does not always boost performance. This assumption was found in previous findings (Bücker, Nuraydin, Simonsmeier, Schneider, \& Luhmann, 2018; Chacko \& Abraham, 2017). Academically poor performing students did not have a lower level of happiness and academically high performing students did not have a high level of well-being. Being happy may not always result in better academic performance. If so, then why several previous findings had shown the significant influence of happiness on academic performance? The absolute answer to this question may be beyond the empirical capability of the present investigation. This paper only argues that, because students' academic performance is a complicated construct, tying it with one single influential factor may be both inappropriate and erroneous effort.

Furthermore, students' academic performance can be a function of multi-layered factors including family issues and demographic status. Several studies in the past supported this assumption. For instance, Mushtaq and Khan (2012) found that familial stress could negatively affect students' academic performance. In addition, students' demographic circumstances may also influence students' academic performance. The study of Tuntiwarodom and Potipiti (2008) had shown that students' financial capability tend to predict students' grades. However, the finding was somehow unconventional. Financially capable students were not academically inclined 
than their less privileged counterparts. In this case, financial status, like happiness, does not always lead to better academic performance. Instead, academic performance could also be a function of cognitive factors. This assumption is anchored upon the previous studies wherein academic success was found to be the result of perceived academic competence and self-determination (Fortier, Vallerand, \& Guay, 1995). Bearing the latter finding into consideration, students' success seemingly independent of intellectual capability. Students could possibly succeed in school if they have the right attitude towards academic tasks regardless of their emotional response to the academic situation.

In the Philippine context where happiness is associated with the motivational drive (Datu \& Valdez, 2012), happy students may be more academically motivated. Internal motivation, in turn, may boost academic performance (Khoshnam, Ghamari, \& Gendavani, 2013. Students who were academically motivated tend to achieve higher academic performance. However, motivation and positive emotions may be the outcome of one's freedom to pursue personally defined goals (Uusiautti, 2014). The relationship between happiness and academic performance found in this study may suggest a bidirectional relationship. Thus, in essence, happiness may not significantly influence students' academic performance but the academic performance itself made students happier. However, although the statistical implication is correct, the generalization on the result should be carried out with caveat and limitations. This study did not perform more robust analysis to test causal relationship. For future research on this area, a mediation or moderation analysis may be more appropriate to clearly identify the variable(s) that determined the direction of the relationship among variables.

The second factor that found to have a significant link with the academic performance was goal concordance. As the result suggests, students who pursued their intended college course had higher academic performance than those who failed to adhere to their college course choice. Taking the result into consideration, the personally defined-goals may have an important role in academic performance (Alispahić, 2013). In the academic context, studies on goal concordance suggest consistent results. The study of Koestner, Lekes, Powers, and Chicoine (2002) had shown the significant role of goal concordance on academic success. Students who took up personally chosen educational goal tend to achieve higher academic performance (Vasalampi, Salmela-Aro, \& Nurmi, 2009).

In the present finding, the same case may be true. Students with self-concordant academic goals could be more academically motivated than students with nonconcordant academic goals. The congruence between goal and intention seem to result in higher emotional state and motivation. In short, being able to follow a goal that is in line with personal interest could potentially maintain positive affect and motivation throughout the attainment of the task. The self-concordant goal does not only serve as a motivational booster but also as an incremental motivational force to improve academic performance along the way (Sheldon \& Houser-Marko, 2001). In short, students enrolled in their personally chosen college courses tend to attain high academic achievements not only at the onset of their college journey but also in the succeeding semesters.

Several studies provide plausible explanations as to how self-concordant goal mediates the trajectory of individuals' performance. First, self-concordant goals seem easier to pursue than the nonconcordant ones (Werner, Milyavskaya, Foxen-Craft, \& Koestner, 2016). Consequently, pursuing an intrinsically primed goal more often result in a successful outcome. In school, intrinsic motivation triggers students to formulate higher goals (Hosseini, Fatemi, Pishghadam, \& Vahidnia, 2014). In fact, intrinsically motivated students tend to spend more time in academic tasks (Chen, Pethtel, Gutowitz, \& Kirk, 2012) which in turn result in better academic performance (Ghamari, 2011). This may imply that parents should consider their children's dreamed college courses. Students' success in school may not be only dependent on their effort and intellectual capabilities but also on the social support they received from their significant others (Koestner et al., 2012; Koestner et al., 2015). In short, academic performance can be viewed as, partly the indirect result of familial support. This assumption stems from the fact that adolescents' decision making is less mature (Cauffman \& Steinberg, 2000). Being less psychologically capable of formulating rigid decisions, adolescents' motivation in pursuing an academic goal can be vulnerable to external influences. Thus, family support may play a very significant role in the students' 
success in the academic endeavor. Although the result of this study cannot be held sufficient and conclusive, the findings highlight the importance of promulgating adolescents' free will to choose their own academic path.

The ability of a self-concordant goal to buffer performance is not only evident in the academic context. Previous studies suggest that, in general, pursuing an intrinsically driven goal would result in an excellent outcome (Gillet, Vallerand, Lafrenie`re, \& Bureau, 2013). Thus, individuals' goals must be in line with their passion and interest (Lee, Mclnerney, Liem, \& Ortiga, 2010). Being able to freely pursue personal goals help individuals to strive harder which result in higher performance (Ntoumanis et al., 2014). Therefore, the ultimate way of achieving success in any undertaking may not be dependent on what is ought to be done. Instead, one should consider the things on which he/she is internally driven and inspired to do.

The current findings accord the tenets of Self-Determination Theory (Ryan \& Deci, 2000). The result offers a further understanding of the dynamics of academic motivation and success. The basic psychological needs (competence, relatedness, autonomy) may have largely shaped college students' academic performance. However, in this study, autonomy is the only component of the psychological needs that clearly offers an explanation of the volatility of college students' academic performance. Primarily because competence and relatedness were not directly tested and included in this study. These two components of psychological needs may have played significant and great role on academic performance. This observation stemmed from the fact that goal concordance only had caused small variability on academic performance score. Thus, there must be latent factors not included in this study that could provide a clearer explanation. Nonetheless, the data show a clear distinction in performance between two groups of college students. The result suggests that students with a self-concordant goal had better academic performance than those with the nonconcordant goal.

Overall, this study shows two important findings. First, happiness and goal concordance were both significantly correlated with college students' academic performance. The direction of the relationships found among the variables under study suggests that happier students tend to have achieved high academic performance. One can assume that happiness, somehow, has something to do with students' school performance and vice versa. Moreover, students with a self-concordant academic goal had higher academic performance than those with a nonconcordant academic goal. Happiness and goal concordance were also found to have significant influence on academic performance. This finding may be a significant contribution of this paper toward understanding college students' academic motivation and success. This partially corroborates with the finding of Deci and Ryan (2000) which suggests that intrinsic motivation boosts performance and happiness. However, as the second important finding of this study suggests, happiness and goal concordance had no significant relationship. The findings may imply one thing - pursuing a self-concordant goal may not necessarily result in happiness contrary to Deci and Ryan assumption. Rather, a self-concordant goal may have buffered academic performance which in turn boosts happiness.

Sheldon and Elliot (1999) had found a similar result. They argued that individuals who were driven by personally defined goals tend to have a higher degree of happiness. In addition, Randler (2009) found an akin finding. The latter study also suggests that students' happiness and interest influence academic performance. The current finding partially echoes similar implication. However, the reason as to why goal concordance and happiness did not establish a significant association with one another is still unclear. At some extent, the current finding, therefore, contradicts the claim of Sheldon et al (2004) which posed that goal concordance predict subjective well-being in many cultures. Hence, this paper suspects that the way Filipinos define happiness is significantly different from the neighboring Asian cultures. Although happiness is universally known as the feeling of joy, the factors which may have been influencing such emotion intricately woven within each culture. In Filipino adolescent students, as found by Datu and Mateo (2012), happiness was tied to personal achievement and the implementation of personal intention where achievement is derived from good grades. The latter qualitative investigation had shown that Filipino adolescents tend to have a positive affect if they were allowed to do what they want. However, whether personal achievement and independence were associated with one another remained unclear due to the fact that the previous finding was extracted from the qualitative accounts. 
The current finding nonetheless, may have somehow unraveled the intricate connection between goal concordance and academic performance with happiness. The connection between these variables may not be cyclical in nature. Instead, it follows a linear direction such that self-concordant academic goal may result in high academic performance, and high academic performance may result in a higher level of happiness. This assumption, however, needs to be tested using a more robust statistical analysis. Nonetheless, the findings of this study may serve as a starting point for future research endeavor and educational interventions.

\subsection{The Role of Self-Concordant Goals on Happiness and Academic Performance}

The test of difference in happiness and academic performance levels between students with self-concordant and nonconcordant goals reveals interesting results. Findings suggest that happiness level did not significantly differ between the two groups of students. However, the significant difference in academic performance was noted between those with a self-concordant and nonconcordant goal. The findings may strengthen the assumption that pursuing a self-concordant goal may not necessarily result in a higher level of happiness. Instead, self-concordant goals boost performance and high performance may, in turn, increase happiness. This might also be the reason why happiness and self-concordant goals did not reveal a significant link.

Although the current findings support the evidence on the link between goal concordance and academic performance (Sheldon \& Houser-Marko, 2001; Koestner, Lekes, Powers, \& Chicoine, 2002; Vasalampi, Salmela-Aro, \& Nurmi, 2009), goal concordance did not show a significant connection with happiness. Rather, happiness seems to be dependent on the outcome of the personally defined goals, not the direct function of being able to pursue a self-concordant goal. The dynamic of the Filipino adolescents' happiness might be worthy to consider. As found by Mateo and Datu (2012), the happiness among Filipino youths was primarily tied with their sense of belongingness and joyful activities. Anchored on this evidence, Filipino college students who pursued self-concordant goal might find school challenges fun and rewarding. Whereas students who were forced to pursue nonconcordant goals may find academic tasks less important. These assumptions emanate from the significant difference in academic performance between the two groups of students (with self-concordant goals and nonconcordant goals) participated in this study.

The findings of this investigation bear two important implications. First, the freedom to pursue a personally defined goal can be a determinant of a successful outcome of a task. If one is constrained from pursuing a self-concordant goal, the performance and the result itself may suffer. Consequently, students who were forced to follow unwanted academic track may find difficulties in their academic journey. Therefore, letting freshmen students decide their academic track in college may be appropriate and necessary. This proposition is supported by the Self-Determination Theory (Ryan \& Deci, 2000). Accordingly, autonomously defined goals are more likely to attain than externally primed goals. The SDT posits that internally driven goals are easier to achieve. Thus, if the tenet is true, students with self-concordant goals will be more academically successful than those with externally driven goals. This investigation conveys an important message to parents and educators that college students' success in school may be dependent on whether or not they implement their desired college courses.

Secondly, happiness may not be the predictor of academic performance. This assumption is also evident in previous studies (Wright \& Cropanzano, 2004; Lyubomirsky, King, \& Diener, 2005; Wright \& Cropanzano, 2000) whereby happiness was found to be connected with task performance. The current finding may shed light on the inconsistent predictive ability of happiness on individuals' ability to carry out the task at hand. Bearing the current finding into consideration, happiness may not, at all times, predict performance. Rather, the interaction might be reciprocal. Better performance outcome may result in higher happiness which in turn result in much higher future performance and happiness.

In sum, although this paper is beyond perfect, this simple endeavor somehow conveys important theoretical and practical implications. First, college students' success in college journey may not be solely dependent on 
their intellectual capability but also on the freedom to follow personally defined academic track. Second, happiness may not directly influence academic performance. Rather, happiness may be the function of high academic performance. Third, goal concordance may not result in a higher level of happiness. Instead, goal concordance may boost academic performance, and high academic performance may in turn buffer happiness.

\section{Conclusion}

The main focus of this study was to determine the association between goal concordance and happiness with academic performance. Secondly, this study also aimed to determine the predictive ability of happiness and goal concordance on college students' academic performance. Taken all the limitations, this study somehow come up with important conclusions. First, goal concordance was associated with college students' academic performance. Similarly, happiness was also found to be related to college students' academic performance. However, goal concordance and happiness had no significant relationship. Furthermore, although both happiness and goal concordance predict academic performance, goal concordance was found to have a greater impact on academic performance. Ultimately, this paper concludes that students who followed their chosen college courses may achieve high academic performance, and high academic performance may, in turn, make them happier.

\subsection{Limitations and Recommendations for Future Studies}

Although the findings bear both empirical and practical implications, possible limitations should not be discarded. The first weakness of this study resides in its design. Since this study is correlational, causation was not directly tested. Thus, the finding only poses the interaction among variables under investigation and therefore cannot suggest how happiness and goal concordance affect academic performance although the predictive ability of happiness and goal concordance were tested. A more robust research design and data analysis may be more appropriate for future research endeavor on this topic. Second, the measure being used in this study may have also contributed to the limitations. Unlike the previous studies, the current research did not use a standardized scale on goal concordance. Instead, goal concordance was simply determined by asking participants whether or not they pursue the college course they want to enroll in college. The researcher acknowledged the fact that the single item assessment on goal concordance variable was way simplistic. Future research may use a more comprehensive measure of goal concordance to address the measurement issue in the current investigation.

Acknowledgment: The Ethics Review Board approved this paper implying that the current investigation followed the implementing rules on ethics in social science research. The author sincerely wants to thank all of those who imparted their knowledge and ethical expertise to make this paper eligible for publication.

\section{References}

Alispahić, S. (2013). Motivational function of plans and goals. Psychological Thought, 6(2), 196-203. https://doi.org/10.5964/psyct.v6i2.80

Blackmon, O. M. (2013, December). Just the stats: Majority of college-bound students select wrong majors. Diverse. Retrieved from https://diverseeducation.com/article/57695/

Boudreaux, M. J., \& Ozer, D. J. (2013). Goal conflict, goal striving, and psychological well-being. Motivation and Emotion, 37, 433-443. https://doi.org/10.1007/s11031-012-9333-2

Bücker, S., Nuraydin, S., Simonsmeier, B. A., Schneider, M., \& Luhmann, M. (2018). Subjective well-being and academic achievement: A meta-analysis. Journal of Research in Personality, 74, 83-94. https://doi.org/10.1016/j.jrp.2018.02.007

Chacko, C. M., \& Abraham, S. S. (2017). Academic performance, self-esteem and happiness among adolescents in Kerala. The International Journal of Indian Psychology, 4(4), 47-54.

Chen, Y., Lee, Y.-T., Pethtel, O. L., Gutowitz, M. S., \& Kirk, R. M. (2012). Age differences in goal concordance, time use, and well-being. Educational Gerontology, 38, 742-752. 
The role of goal concordance on happiness and college students' academic performance https://doi.org/10.1080/03601277.2011.645424

Cauffman, E., \& Steinberg, L. (2000). (Im)maturity in adolescence: Why adolescents may be less culpable than adults. Behavioral Sciences and the Law, 18(6), 741-760. https://doi.org/10.1002/bsl.416

Daniels, L. M., Stupnisky, R. H., Haynes, T. L., Perry, R. P., Newall, N. E., \& Pekrun, R. (2009). A longitudinal analysis of achievement goals: From affective antecedents to emotional effects and achievement outcomes. Journal of Educational Psychology, 101(4), 948-963. https://doi.org/10.1037/a0016096

Datu, J A. (2013). Be happy and believe in your capacity: Establishing link between subjective well-being and self-efficacy among Filipino adolescents. International Journal of Research Studies in Psychology, 2(3), 3-10. https://doi.org/10.5861/ijrsp.2012.206

Datu, J. A., \& Mateo, N. J. (2012). Investigating happiness through a psychoanalytic social lens: Perspectives from Filipino adolescents. Asian Journal of Social Sciences and Humanities, 1(4), 232-242. https://doi.org/10.5861/ijrsp.2012.251

Datu, J. A. D., \& Valdez, J. P. M. (2012). Exploring Filipino adolescents' conception of happiness. International Journal of Research Studies in Psychology, 1(3), 21-29. https://doi.org/10.5861/ijrsp.2012.251

Deci, E. L., \& Ryan, R. M. (2000). The "what" and "why" of goal pursuits: Human needs and the self-determination of behavior. Psychological Inquiry, 11(4), 227-268. https://doi.org/10.1207/S15327965PLI1104_01

Deci, E. L., Ryan, R. M., Gagné, M., Leone, D. R., Usunov, J., \& Kornazheva, B. P. (2001). Need satisfaction, motivation, and well-being in the work organizations of a former Eastern Bloc Country: A cross-cultural study of self-determination. Personality and Social Psychology Bulletin, 27(8), 930-942. https://doi.org/10.1177/0146167201278002

Fortier, M. S., Vallerand, R. J., Guay, F. (1995). Academic motivation and school performance: Toward a structural model. Contemporary Educational Psychology, 20, 257-274. https://doi.org/10.1006/ceps.1995.1017

Ghamari, M. (2011). The relationship of internal motivation components and academic achievement among high school students. International Journal of Human Resource Studies, 1(2), 89-97. https://doi.org/10.5296/ijhrs.v1i2.1111

Gillet, N., Vallerand, R. J., Lafrenie re, M.-A. K., \& Bureau, J. S. (2013). The mediating role of positive and negative affect in the situational motivation-performance relationship. Motivation and Emotion, 37(3), 465-479. https://doi.org/10.1007/s11031-012-9314-5

Harackiewicz, J. M., \& Hulleman, C. S. (2010). The importance of interest: The role of achievement goals and task values in promoting the development of interest. Social and Personality Psychology Compass, 4(1), 42-52. https://doi.org/10.1111/j.1751-9004.2009.00207.x

Hassanzadeh, R., \& Mahdinejad, G. (2013). Relationship between happiness and achievement motivation: A case of university students. Journal of Elementary Education, 23(1), 53-65.

Headey, B. (2006). Life goals matter to happiness: A revision of Set-Point Theory. Retrieved from http://www.diw.de/documents/publikationen/73/diw_01.c.68696.de/diw_sp0055.pdf

Hidi, S., \& Harackiewicz, J. M. (2000). Motivating the academically unmotivated: A critical issue for the 21st century. Review of Educational Research, 70(2), 151-179. https://doi.org/10.3102/00346543070002151

Hosseini, F. A., Pishghadam, R., \& Vahidnia, F. (2014). The role of goal-setting theory on Iranian EFL learners' motivation and self-efficacy. International Journal of Research Studies in Language Learning, 3(2), 69-84. https://doi.org/10.5861/ijrsll.2013.528

Joussemet, M., Landry, R., \& Koestner, R. (2008). A self-determination theory on parenting. Canadian Psychological Association, 49(3), 194-200. https://doi.org/10.1037/a0012754

Judge, T. A., Bono, J. E., Erez, A., \& Locke, E. A. (2005). Core self-evaluations and job and life satisfaction: The role of self-concordance and goal attainment. Journal of Applied Psychology, 90(2), 257-268. https://doi.org/10.1037/0021-9010.90.2.257

Khoshnam, A. H., Ghamari, M., \& Gendavani, A. G. (2013). The relationship between intrinsic motivation and happiness with academic achievement in high school students. International Journal of Academic Research in Business and Social Sciences, 3(11), 330-336. https://doi.org/10.6007/IJARBSS/v3-i11/342 
Koestner, R., Lekes, N., Powers, T. A., \& Chicoine, E. (2002). Attaining personal goals: Self-concordance plus implementation intentions equals success. Journal of Personality and Social Psychology, 83(1), 231-244. https://doi.org/10.1037/0022-3514.83.1.231

Koestner, R., Otis, N., Powers, T. A., Pelletier, L., \& Gagnon, H. (2008). Autonomous motivation, controlled motivation, and goal progress. Journal of Personality, 76(5), 1201-1230. https://doi.org/10.1111/j.1467-6494.2008.00519.x

Koestner, R., Powers, T. A., Carbonneau, N., Milyavskaya, M., \& Chua, S. N. (2012). Distinguishing autonomous and directive forms of goal support: Their effects on goal progress, relationship quality, and subjective well-being. Personality and Social Psychology Bulletin, 38(12), 1609-1620. https://doi.org/10.1177/0146167212457075

Koestner, R., Powers, T. A., Milyavskaya, M., Carbonneau, N., \& Hope, N. (2015). Goal internalization and persistence as a function of autonomous and directive forms of goal support. Journal of Personality, 83(2), 179-190. https://doi.org/10.1111/jopy.12093

Lee, J. Q., McInerney, D. M., Liem, G. A. D., \& Ortiga, Y. P. (2010). The relationship between future goals and achievement goal orientations: An intrinsic-extrinsic motivation perspective. Contemporary Educational Psychology, 35(4), 264-279. https://doi.org/10.1016/j.cedpsych.2010.04.004

Lyubomirsky, S., King, L., \& Diener, E. (2005). The benefits of frequent positive affect: Does happiness lead to success? Psychological Bulletin, 131(6), 803-855. https://doi.org/10.1037/0033-2909.131.6.803

Lyubomirsky, S., \& Lepper, H. S. (1999). A measure of subjective happiness: Preliminary reliability and construct validation. Social Indicators Research, 46, 137-155. https://doi.org/10.1023/A:1006824100041

Malik, M., Nordin, N., Zakaria, A., \& Sirun, N. (2013). An exploratory study on the relationship between life satisfaction and academic performance among undergraduate students of UiTM, Shah Alam. Procedia Social and Behavioral Sciences, 90, 334 - 339. https://doi.org/10.1016/j.sbspro.2013.07.099

Manzoor, A., Siddique, A., Riaz, F., \& Riaz, A. (2014). Determining the impact of subjective well-being on academic achievement of children in district Faisalabad. Mediterranean Journal of Social Sciences, 5(23), 2673-2678. https://doi.org/10.5901/mjss.2014.v5n23p2673

Mateo, N. J. C., \& Datu, J. A. D. (2012). Conceptualizing happiness using Choice Theory. International Journal of Research Studies in Psychology, 1(3), 31-36. https://doi.org/10.5861/ijrsp.2012.263

Michalak, J., Klappheck, M. A., \& Kosfelder, J. (2004). Personal goals of psychotherapy patients: The intensity and the "why" of goal-motivated behavior and their implications for the therapeutic process. Psychotherapy Research, 14(2) 193-209. https://doi.org/10.1093/ptr/kph017

Mohammadi, A. (2015). The relationship between happiness and confidence with student achievement (case study elementary schools in Kangan). International Journal of Innovative Science, Engineering and Technology, 2(12), 790-796.

Mushtaq, I., \& Khan, S. N. (2012). Factors affecting students' academic performance. Global Journal of Management and Business Research, 12(9), 16-22.

Neuville, S., Frenay, M., \& Bourgeois, E. (2007). Task value, self-efficacy and goal orientations: Impact on self-regulated learning, choice and performance among university students. Psychologica Belgica, 47(1), 95-117. https://doi.org/10.5334/pb-47-1-95

Ng, J. Y. Y., Ntoumanis, N., Thøgersen-Ntoumani, C., Deci, E. L., Ryan, R. M., Duda, J. L., \& Williams, G. C. (2012). Self-determination theory applied to health contexts: A meta-analysis. Perspectives on Psychological Science, 7(4), 325-340. https://doi.org/10.1177/1745691612447309

Niemiec, C. P., Lynch, M. F., Vansteenkiste, M., Bernstein, J., Deci, E. L., \& Ryan, R. M. (2006). The antecedents and consequences of autonomous self-regulation for college: A self-determination theory perspective on socialization. Journal of Adolescence, 29, 761-775. https://doi.org/10.1016/j.adolescence.2005.11.009

Niemiec, C. P., \& Ryan, R. M. (2009). Autonomy, competence, and relatedness in the classroom: Applying self-determination theory to educational practice. Theory and Research in Education, 7(2), 133-144. https://doi.org/10.1177/1477878509104318 
The role of goal concordance on happiness and college students' academic performance

Nonis, S. A., \& Hudson, G. I. (2006). Academic performance of college students: Influence of time spent studying and working. The Journal of Education for Business, 81(3), 151-159. https://doi.org/10.3200/JOEB.81.3.151-159

Ntoumanis, N., Healy, L. C., Sedikides, C., Duda, J., Stewart, B., Smith, A., \& Bond, J. (2014). When the going gets tough: The "why" of goal striving matters. Journal of Personality, 82(3), 225-236. https://doi.org/10.1111/jopy.12047

Panahi, M., Panahi, H., \& Sobhani, H. (2015). Impacts of positive thinking skills up on happiness and academic performance of first level high school girls of Shirvan. International Academic Journal of Innovative Research, 2(9), 44-52.

Pekrun, R., Elliot, A. J., \& Maier, M. A. (2009). Achievement goals and achievement emotions: Testing a model of their joint relations with academic performance. Journal of Educational Psychology, 101(1), 115-135. https://doi.org/10.1037/a0013383

Rahimi Pordanjani, T., Yahyanezhad, F., \& Moharer, A. (2014). Self -efficacy, academic achievement and happiness. International Journal of Education and Applied Sciences, 1(4), 181- 188.

Randler, C. (2009). Association between emotional variables and school achievement. International Journal of Instruction, 2(2), 3-10.

Ryan, R. M., \& Deci, E. L. (2000). Self-determination theory and the facilitation of intrinsic motivation, social development, and well-being. American Psychologist, 55(1), 68-78. https://doi.org/10.1037/0003-066X.55.1.68

Senécal, C., Koestner, R., \& Vallerand, R. J. (1995). Self-regulation and academic procrastination. The Journal of Social Psychology, 135(5), 607-619. https://doi.org/10.1080/00224545.1995.9712234

Sheldon, K.M., \& Elliot, A.J. (1999). Goal striving, need satisfaction, and longitudinal well-being: The self-concordance model. Journal of Personality and Social Psychology, 76(3), 482-497. https://doi.org/10.1037/0022-3514.76.3.482

Sheldon, K. M., Elliot, A. J., Ryan, R. M., Chirkov, V., Kim, Y., Wu, C., ... Sun, Z. (2004). Self-concordance and subjective well-being in four cultures. Journal of Cross-Cultural Psychology, 35(2), 209-223. https://doi.org/10.1177/0022022103262245

Sheldon, K. M., \& Houser-Marko, L. (2001). Self-concordance, goal attainment, and the pursuit of happiness: Can there be an upward spiral? Journal of Personality and Social Psychology, 80(1), 152-165. https://doi.org/10.1037//0022-3514.80.1.152

Soule, B. J. (2009). Determinants of academic achievement and intention to complete the program among PGA Golf Management students. UNLV Theses, Dissertations, Professional Papers, and Capstones, 124. Retrieved from https://digitalscholarship.unlv.edu/thesesdissertations/124

Sung, K.-Y., \& Tsai, H.-M. (2014). Motivation and learner variables: Group differences in college foreign language learners' motivations. International Journal of Research Studies in Language Learning, 3(2), 43-54. https://doi.org/10.5861/ijrs1l.2013.561

Tabbodi, M., Rahgozar, H., \& Abadi, M. M. M. (2015). The relationship between happiness and academic achievements. European Online Journal of Natural and Social Sciences, 4(1), 241-246.

Tuntiwarodom, L., \& Potipiti, T. (2008). Determinants of happiness and academic performance of economics students. Chulalongkorn Journal of Economics, 20(3), 183-200.

Uusiautti, S. (2014). On the positive connection between success and happiness. International Journal of Research Studies in Psychology, 3(1), 85-96. https://doi.org/10.5861/ijrsp.2013.509

Vansteenkiste, M., Lens, W., \& Deci, E. L. (2006). Intrinsic versus extrinsic goal contents in self-determination theory: Another look at the quality of academic motivation. Educational Psychologist, 41(1), 19-31. https://doi.org/10.1207/s15326985ep4101_4

Vasalampi, K., Salmela-Aro, K., \& Nurmi, J.-E. (2009). Adolescents's self-concordance, school engagement, and burnout predict their educational trajectories. European Psychologist, 14(4), 332-341. https://doi.org/10.1027/1016-9040.14.4.332

Veenhoven, R. (2010). Greater happiness for a greater number is that possible and desirable? Journal of Happiness Studies, 11(5), 605-629. https://doi.org/10.1007/s10902-010-9204-z 
Werner, K. M., Milyavskaya, M., Foxen-Craft, E., \& Koestner, R. (2016). Some goals just feel easier: Self-concordance leads to goal progress through subjective ease, not effort. Personality and Individual Differences, 96, 237-242. https://doi.org/10.1016/j.paid.2016.03.002

Wright, T. A., \& Cropanzano, R. (2000). Psychological well-being and job satisfaction as predictors of job performance. Journal of Occupational Health Psychology, 5(1), 84-94. https://doi.org/10.1037/1076-8998.5.1.84

Wright, T. A., \& Cropanzano, R. (2004). The role of psychological well-being in job performance: A fresh look at an age-old quest. Organizational Dynamics, 33(4), 338-351.

https://doi.org/10.1016/j.orgdyn.2004.09.002 